\title{
The 15th International Conference on Modern Trends in Activation Analysis (MTAA-15) at BARC, Mumbai, India: Preface
}

\author{
R. Acharya ${ }^{1,3} \cdot$ A. V. R. Reddy ${ }^{2}$ P. K. Pujari ${ }^{1,3}$
}

Published online: 11 August 2020

๑) Akadémiai Kiadó, Budapest, Hungary 2020

The determination of mass fraction of elements at major to trace levels with high precision and accuracy is a challenge. Activation analysis techniques in general and NAA, PGNAA and CPAA in particularl are suitable for such purposes. These techniques are applied to diverse samples in different fields including geology, life sciences, environmental sciences, archaeology, metallurgy, material sciences, agriculture, nuclear technology, and forensic sciences. In addition to total mass fraction, it is important to characterize isotopic composition and chemical speciation of elements. It is also important to develop newer methodologies in activation analysis to deal with complex matrix samples for various elements of interest and aslo to achieve improved sensitivities and detection limits compared to complementary nuclear/radioanalytical as well as conventional analytical techniques. International Conference on Modern Trends in Activation Analysis (MTAA) is conducted once in every 4 years, since its inception in 1961, to discuss recent developments and applications as well as future prospects of activation analysis. The MTAA conferences, in reverse chronological order, were held at: Bhabha Atomic Research Centre, Mumbai, India (MTAA-15, 2019), Delft University of Technology, Delft, The Netherlands (MTAA-14, 2015), Texas A\&M University, College Station, USA (MTAA-13, 2011), Tokyo Metropolitan University, Hachioji, Japan (MTAA12, 2007), University of Surrey, Guildford, UK(MTAA-11, 2004), National Institutes of Health in Bethesda, Maryland, USA (MTAA-10, 1999), Korea Atomic Energy Research Institute, Seoul, South Korea (MTAA-9, 1995), Technical

R. Acharya

racharya@barc.gov.in; racharyabarc@gmail.com

1 Radiochemistry Division, Bhabha Atomic Research Centre, Trombay, Mumbai 400085, India

2 Analytical Chemistry Division, Bhabha Atomic Research Centre, Trombay, Mumbai 400085, India

3 Department of Atomic Energy, Homi Bhabha National Institute, Mumbai 400094, India
University of Vienna Atominstitut, Vienna, Austria (MTAA8, 1991), Riso National Laboratory, Copenhagen, Denmark (MTAA-7, 1986), University of Toronto, Toronto, Canada (MTAA-6, 1981), Technical University of Munich, Munich, Germany (MTAA-5, 1976), CNRS du Cyclotron, Saclay, France (MTAA-4, 1972), National Bureau of Standards, Maryland, USA (MTAA-3, 1968), Texas A\&M University, College Station, USA (MTAA-2, 1965) and Texas A\&M University, College Station, USA (MTAA-1, 1961).

The MTAA-15 was the very first MTAA conference ever held in India and it was organized by Bhabha Atomic Research Centre (BARC) during November 17-22, 2019 at the Department of Atomic Energy (DAE) Convention Centre, Anushaktinagar, Mumbai-400094. It was organized in association with the International Committee on Activation Analysis (ICAA) and Indian Association of Nuclear Chemists \& Allied Scientists (IANCAS) with partial funding from the Board of Research in Nuclear Sciences (BRNS), DAE, Government of India. The scope of MTAA-15 included areas such as Neutron activation analysis (NAA), Prompt gamma-ray NAA (PGNAA), Charged particle activation analysis (CPAA), Photon activation analysis (PAA), Fast neutron activation analysis (FNAA), $k_{0}$-based conventional $\&$ internal monostandard NAA \&PGNAA, Preconcentration, radiochemical, chemical \&speciation NAA, Research reactors, accelerators \& other facilities for activation analysis, Instrumentation for activation analysis, Applications of activation analysis to various fields, Applications of activation products, Applications to reference materials \& QA/ $\mathrm{QC}$ in measurements, and Complementary radioanalytical techniques.

Prior to the start of MTAA-15 Conference at BARC, a One-Day School on "Conventional and $k_{0}$-based NAA (SNAA-2019)" was organized on Sunday, 17 November 2019 for the benefit of about 100 younger participants and research scholars. SNAA-2019 was inaugurated by Dr. D.D. Sood (Chief Guest), former Director of Radiochemistry and Isotope Group (RC\&IG), BARC. Other distinguished 
guests present were: Dr. P.K. Pujari, Director of RC\&IG, BARC (Chair, MTAA-15), Dr. A.V.R. Reddy (Chair, Technical Committee MTAA-15), Dr. H. Pal, Associate Director of Chemistry Group, BARC, Dr. R. Acharya (Convener, MTAA-15) and Shri K.C. Jagadeesan (Secretary, SNAA2019). There were six technical lectures by experts from abroad and India and were presented by Dr. Zsolt Revay, Prof. A. Chatt, Dr. R.R. Greenberg, Dr. R Acharya, Dr. Borut Smodis and Dr. R. van Sluijs.

The inaugural function of MTAA-15, held on 18 th November 2019, was presided by Dr. P.K. Pujari and inaugurated by Shri Sujay Bhattacharya, Director of the Reactor
Projects Group (RPG), BARC as the Chief Guest. Other dignitaries who spoke in the inaugural function were: Prof. A. Chatt, President of ICAA, Dr. A.V.R Reddy, Dr. R. Acharya, and Dr. K K Swain (Secretary, MTAA-15) (Fig 1). About 250 participants including 40 overseas delegates from 23 countries (excluding India) participated in thisconference (Fig 2). Success of any conference depends on its technical content. It was satisfying that a large number of contributions were received from abroad, Indian institutes and various DAE units including BARC. The book of abstracts of MTAA-15 was released during inaugural function (Fig 1). Technical program of the conference consisted of 20 invited

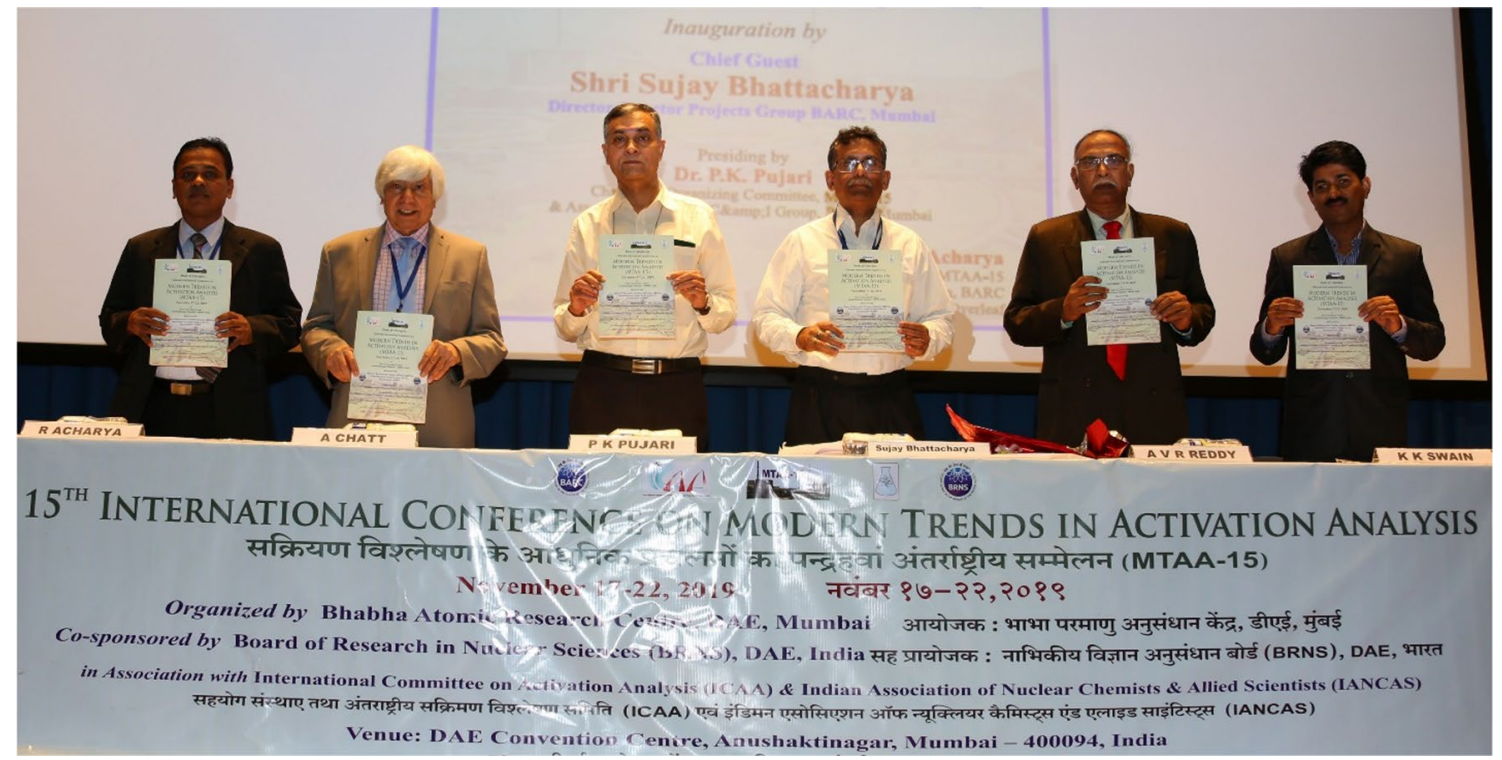

Fig. 1 Inaugural Function of MTAA-15 Conference on November 18, 2019 and Release of Conference Abstract Book (Left to Right: Dr. R. Acharya (Convener of MTAA-15), Prof. A. Chatt (President of ICAA
\& Associate Editor of JRNC), Dr. P.K. Pujari (Chair of MTAA-15), Shri S. Bhattacharya (Chief Guest), Dr. A.V.R. Reddy (Technical Chair of MTAA-15) \& Dr. K.K. Swain (Secretary of MTAA-15))

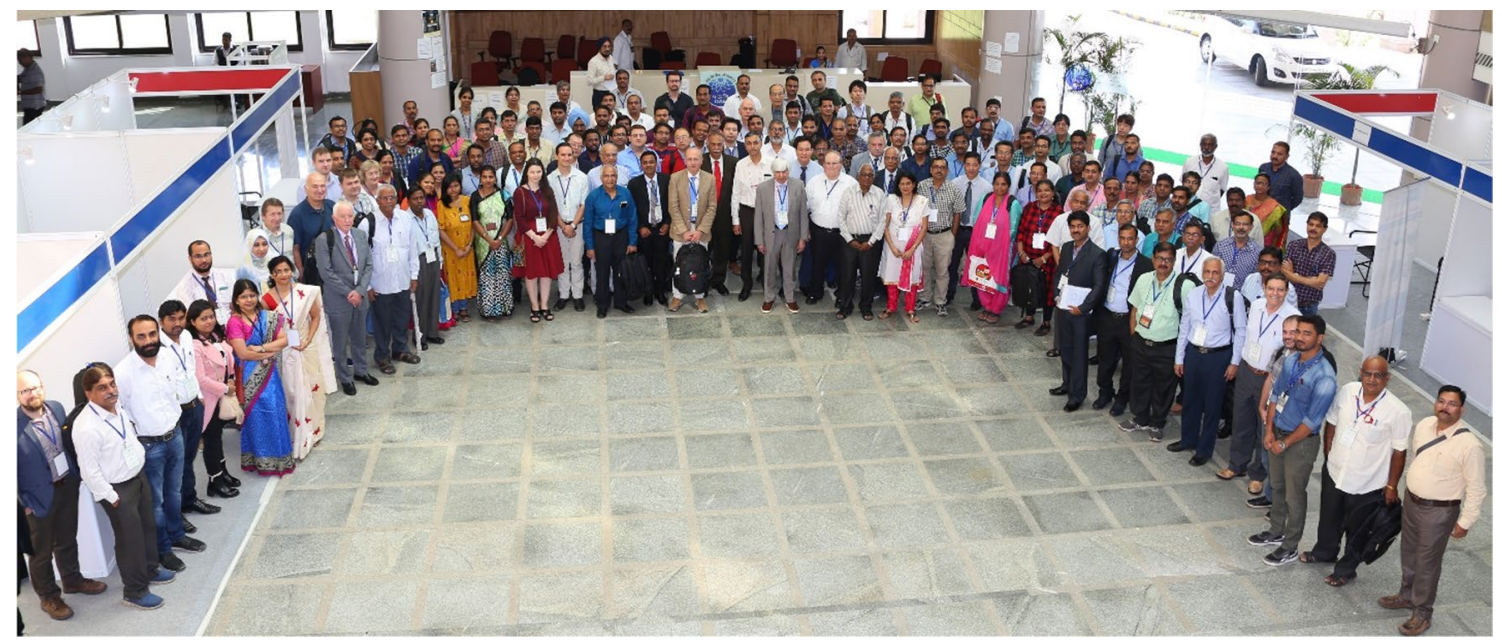

Fig. 2 Group Photo of Participants of MTAA-15 Conference at DAE Convention Centre, Mumbai 
talks, 2 special invited lectures, 8 invited orals by young scientists along with 174 contributed abstarcts ( 30 orals and 144 poster presentations) presented in 12 technical sessions and two poster sessions. We thank all the invited speakers for their talks with excellent review and current trends in respective fields (one page abstract of each talk is included in the Book of Abstarcts of MTAA-15). The names of the Session Chairs of MTAA-15 were: Dr. R.R. Greenberg, Dr. B. Smodis, Dr. M. Ebihara, Dr. B. Tomlin, Dr. V.P. Kolotov, Dr. G. Kennedy, Prof. A. Chatt, Dr. J. Kucera, Dr. Lav Tandon, Dr. D.D. Sood, Dr. V. Venugopal, Dr. S.B. Manohar, Dr. S.K. Aggarwal, Dr. B.S. Tomar, Dr. V. Bhasin, Dr. P.D. Naik, Dr. S. Kapoor, Dr. A.K. Tyagi, Dr. A. Dash, Dr. S. Kannan, Dr. M.S. Kulkarni, Prof. A.N. Garg, Dr. B.K. Nayak and Shri S.K. Jha.

On 21st November 2019, a theme based technical program on "Applications of Activation Analysis \& Activation Products for Forensic Science and Societal Benefits" was held at K.C. College, Mumbai as a part of the DAE outreach program. Dr. A.K. Mohanty, Director of BARC was the Chief Guest \& delivered the keynote address. Other dignitaries present in this one-day program were Dr. Zsolt Revay, Secretary of ICAA \& Editor-in-Chief of J. Radioanalytical \& Nuclear Chemistry (JRNC), Dr. Pujari, Dr. Reddy, Dr. Acharya, and distinguished guests from the institute including Dr. Hemlata K Bagla, Principal of K.C. College, Mr. Anil Harish, Trustee and Member of Hyderabad (Sind) National Collegiate (H(S)NC) Board and Dr. Kishu Mansukhani, President and Trustee of H(S)NC Board. Chief Guest released the MTAA-15 Souvenir (Special Bulletin of IANCAS with selected articles by experts) on "Utilization of Research Reactors in the R\&D works on NAA and
Production of Activation Products for Societal Benefits" (Fig 3). It was attended by a large number of students and young scientists along with MTAA-15 registered participants (Fig 4). We thank the authorities of K.C. College and $\mathrm{H}(\mathrm{S}) \mathrm{NC}$ Board for their support and jointly hosting with BARC this One-Day Technical Program.

A panel discussion on "Non-reactor-based Activation Analysis" was organized before the closing ceremony with Prof. A. Chatt as the Chair. The closing ceremony was held on November 22, 2019, in which Prof. Srikumar Banerjee, Chancellor of the Homi Bhabha National Institute (HBNI), former Chairman of the Atomic Energy Commission (AEC) and Chairman of BRNS (Fig 5), delivered the valedictory address and distributed best oral and poster awards, judged by two separate committees, mostly to the PhD students \& young researchers. Other dignitaries who were present in the valedictory function were Prof. A. Chatt, Dr. Zsolt Revay, D. V. Venugopal, Dr. A.V.R. Reddy, Dr. Borut Smodis, Dr. Jan Kucera, Dr. R. Acharya, and Dr. R.S Sathyapriya (Secretary, MTAA-15). The dignitaries summarized the technical contents and overall organization of MTAA-15 conference and also the future prospects of activation analysis.

The ICAA meeting was held on 19th November, 2019. Prof. A. Chatt presided over the meeting and Dr. Zsolt Revay recorded the minutes. During the meeting elections for the next (term 2019-2023) President and Secretary of ICAA were held among other items. The $\mathrm{k}_{0}$ International Scientific Committee ( $\mathrm{k}_{0}$-ISC) Meeting was also held on 20th November 2019. Dr. Borut Smodis chaired the meeting and he discussed various agenda items including organization of next $\mathrm{k}_{0}$ international Users Workshop in Slovenia in the year 2021.

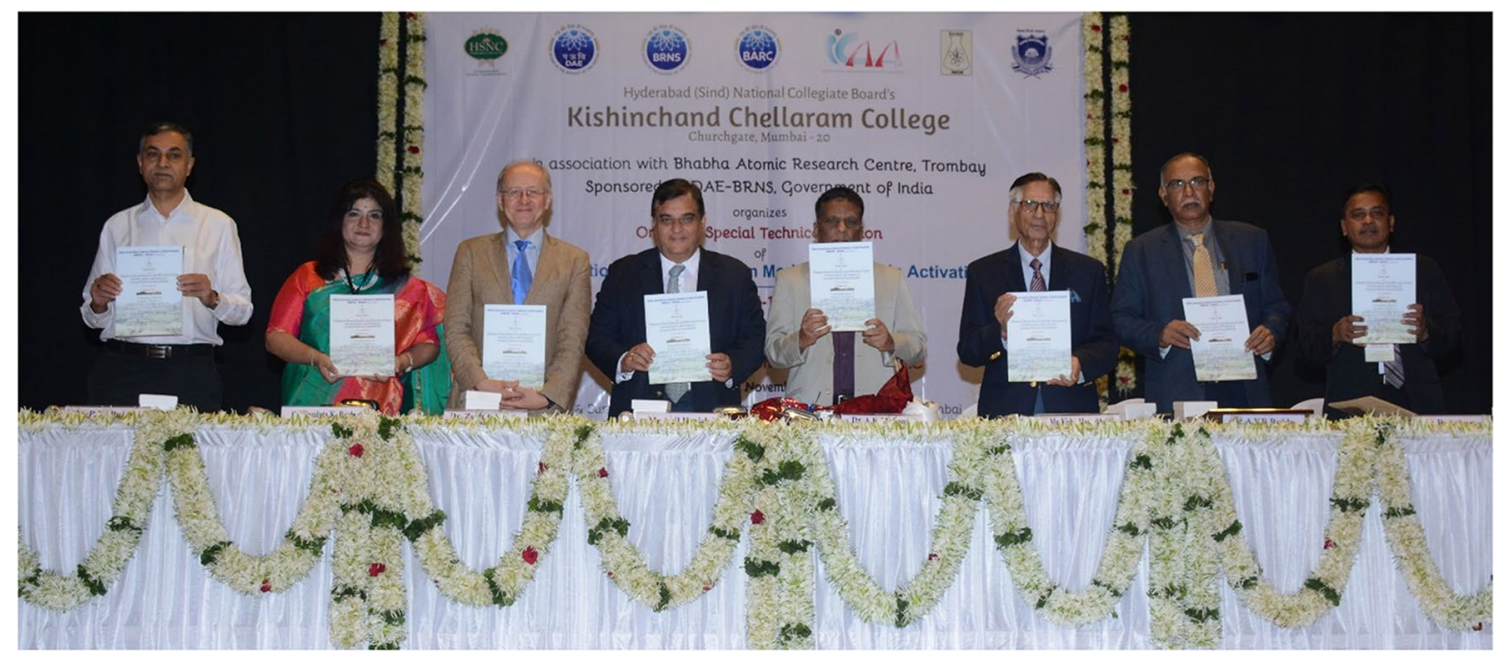

Fig. 3 One-Day Theme Meeting of MTAA-15 at K.C. College, Mumbai and Release of IANCAS Special Bulletin (Left to Right: Dr. P.K. Pujari, Dr. Hemlata K. Bagla (Principal of K.C. College), Dr. Zsolt Revay (Editor-in-Chief of JRNC and Secretary of ICAA), Mr. Anil
Harish, Trustee and Member, H(S)NC Board, Dr. A.K. Mohanty, Director of BARC (Chief Guest and Keynote Speaker), Dr. Kishu Mansukhani, President and Trustee of H(S)NC Board, Dr. AVR Reddy \& Dr. R. Acharya) 


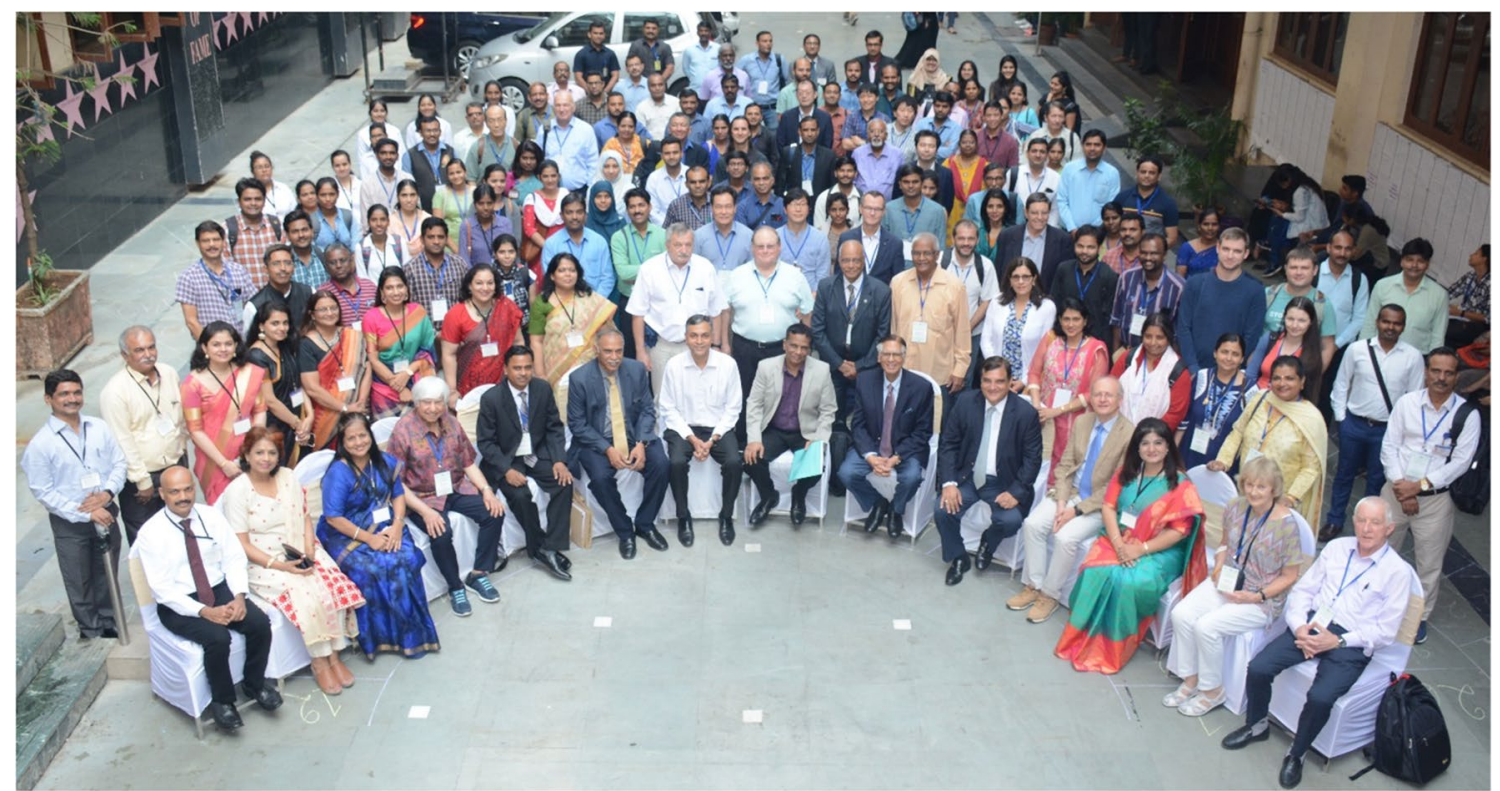

Fig. 4 Group Photo of Participants of MTAA-15 at the One-Day Theme Meeting at K.C. College, Mumbai

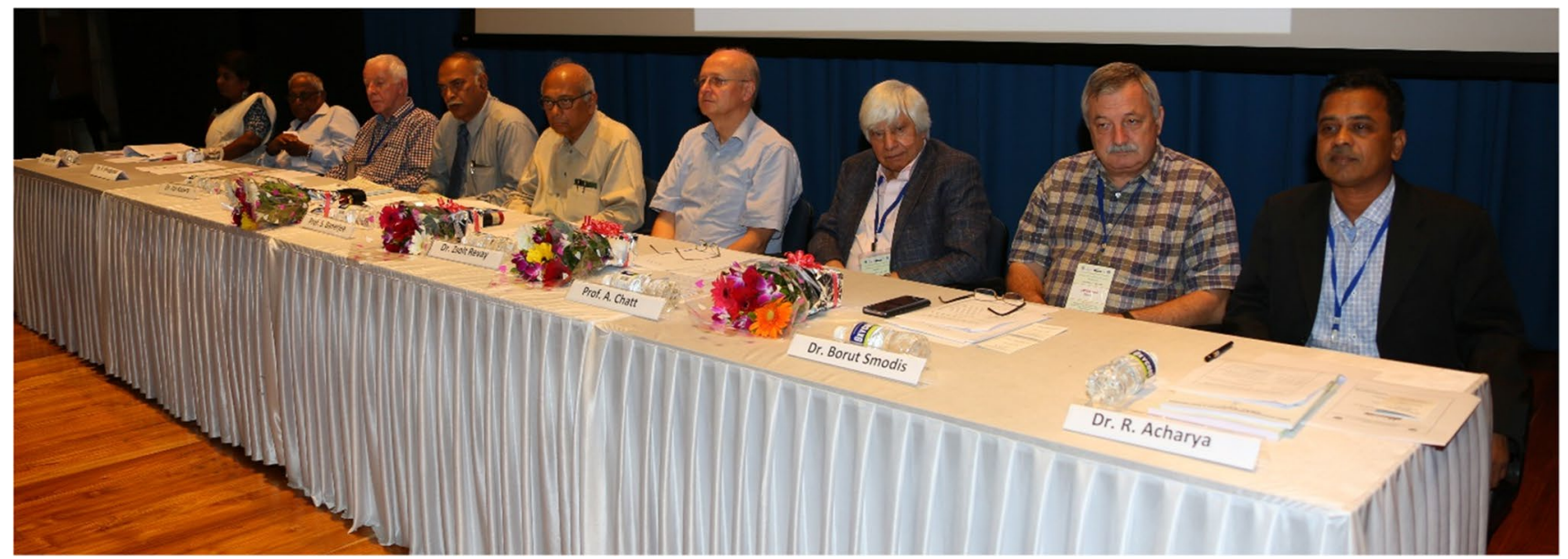

Fig. 5 Closing Function of MTAA-15 Conference (Left to Right: Dr. Sathyapriya R.S. (Secretary), Dr. V. Venugopal, Dr. Jan Kucera, Dr. A.V.R. Reddy, Prof. Srikumar Banerjee (Chief Guest \& Former

Conference of this scale cannot be successful without the help and support from many corners. On behalf of the MTAA-15 Organizing Committee, we thank Chemistry and Isotope Group Board, Trombay Council, BARC and DAE for the permission to hold the Conference at BARC. We also thank BRNS, DAE and Prof. Srikumar Banerjee for granting financial support. We thank Dr. K.N. Vyas, Chairman of Atomic Energy Commission (AEC) and Secretary of DAE, India, Dr. A.K. Mohanty, Director, BARC and all Advisory Committee members for their support. We thank External Relations (ER), DAE and Ministry of External Affairs (MEA), Government of India, Home Department of
Chairman of AEC, India), Dr. Zsolt Revay, Prof. A. Chatt, Dr. Borut Smodis \& Dr. R. Acharya)

Maharashtra State Government, for their timely support for permission as well as for helping in getting visas of participants from abroad. We sincerely thank all the Unit Heads of DAE, Group Directors and Division Heads, BARC and other units of DAE, President and Members of IANCAS, Head of SIRD, BARC, Organizing, Technical, Local Organizing (Chair Dr. S Jeyakumar, Cordinators of all Sub-Committees and all team members), Souvenir and Exhibition Committee members for their support. We sincerely thank all distinguished guests, technical session chairs, Chairs (Prof. Chatt and Dr. Reddy) and committee members for selection of the best oral and poster presentations awards. We also thank 
Director, Directorate of Construction, Services\& Estate Management (DCSEM), and Management, DAE Convention Centre (Conference Venue), Controller, BARC, Trombay Council (TC) and Public Relation Officer (PRO) Office, TC \& TSC Office and Secretary, TC\&TSC, BARC, DEO/APO (Trasport), BARC, Administrative Officer (III), BARC Guest House, Trombay Police, and security personnel (BARC \& DCSEM) for their necessary support. Special thanks to all sponsors and exhibitors for their support through IANCAS to bring out the MTAA-15 Souvenir. Thanks are due to all the office and technical staff of Radiochemistry and Isotope Group and Chemistry Group, BARC for their help and support towards the successful organization of MTAA-15.

We are thankful to Dr. Zsolt Revay, Prof. A. Chatt, and Dr. Tibor Kocsor of JRNC for their continuous support in permitting us as well as for bringing out this Special Issue of JRNC containing 35 full papers of selected abstracts presented in MTAA-15 Conference. Each manuscript was reviewed by two/three reviewers as per the JRNC guidelines for regular articles. We thank all reviewers for sparing their valuable time and making this special issue possible.

Guest Editors:

R. Acharya, Convener, Organizing Committee, MTAA$15 \&$ Head, Nuclear Analytical \& Accelerator Chemistry Section, RCD, BARC

A.V.R. Reddy, Chair, Technical Committee, MTAA-15 \& Former Head, Analytical Chemistry Division, BARC

P.K. Pujari, Chair, Organizing Committee, MTAA-15 \& Director, Radiochemistry and Isotope Group \& Head, RCD, BARC

Publisher's Note Springer Nature remains neutral with regard to jurisdictional claims in published maps and institutional affiliations. 